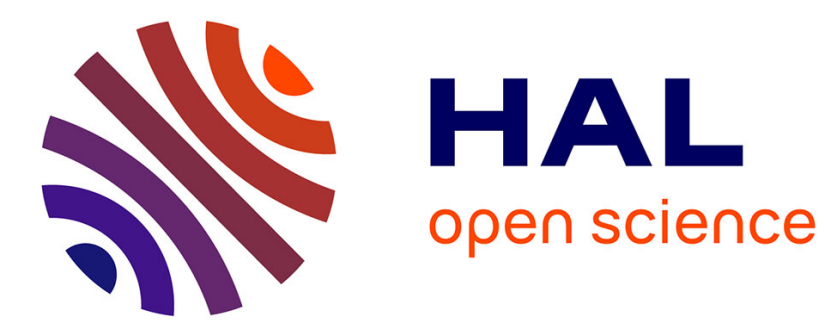

\title{
Tensile properties of polypropylene fibers
}

\author{
Emmanuel Richaud, Bruno Fayolle, Peter D. Davies
}

\section{To cite this version:}

Emmanuel Richaud, Bruno Fayolle, Peter D. Davies. Tensile properties of polypropylene fibers. Handbook of Properties of Textile and Technical Fibres : The Textile Institute Book Series, Elsevier, pp.515543, 2018, 978-008101272-7;978-008101886-6. 10.1016/B978-0-08-101272-7.00014-6 . hal-02569111

\section{HAL Id: hal-02569111 \\ https://hal.science/hal-02569111}

Submitted on 11 May 2020

HAL is a multi-disciplinary open access archive for the deposit and dissemination of scientific research documents, whether they are published or not. The documents may come from teaching and research institutions in France or abroad, or from public or private research centers.
L'archive ouverte pluridisciplinaire HAL, est destinée au dépôt et à la diffusion de documents scientifiques de niveau recherche, publiés ou non, émanant des établissements d'enseignement et de recherche français ou étrangers, des laboratoires publics ou privés. 


\title{
Tensile properties of polypropylene fibers
}

\author{
Emmanuel Richaud ${ }^{1}$, Bruno Fayolle ${ }^{1}$, Peter Davies ${ }^{2}$ \\ ${ }^{1}$ Laboratoire PIMM, Paris, France; ${ }^{2}$ IFREMER Centre Bretagne, Plouzané, France
}

\subsection{Introduction}

Polypropylene (PP) was known before the Second World War, but only in its noncrystalline (atactic) form, which displays the characteristics of an unvulcanized rubber with the inconvenience of being practically unvulcanizable. Polypropylene became an industrially interesting polymer when Natta discovered a way to obtain a stereoregular structure using stereospecific catalysts (1954). PP is thus the last commodity polymer (the others being polyethylene, poly(vinylchloride), and polystyrene) to appear on the market. Its fiber-forming properties were rapidly recognized. It was first used to replace vegetal fibers such as hemp in cordage. However, it invaded progressively other important markets: carpets, filters including cigarette filters, geotextiles, agriculture bays, camouflage technology, disposable diapers, feminine hygiene products, surgical gowns, prosthetic meshes, and additives for concrete (Aizenshtein and Efremov, 2006; Isaeva et al., 1997; Yu et al., 2007; Goldstein, 1999; Moisidis et al., 2000; Sadiqul Islam and Das Gupta, 2016). The world consumption increased from 1 to more than 6 million tons from 1980 to 2010, with an average rate of increase about 100,000 tons per year (Qin, 2014). PP fibers ranked in second place after polyester fibers (Aizenshtein, 2004, 2006). Their growth could be slowed down, in a more or less remote future, by the increase in oil price and the revival of natural fibers but these trends are, in reality, very difficult to predict.

\subsection{Polypropylene structure and properties}

PP results from the polymerization of propylene. There actually are three kinds of stereoisomers (Fig. 14.1). The polymerization conditions determine the degree of chain stereoregularity, the molecular weight distribution, the powder morphology, and, finally, the comonomer content and its distribution in the chains (Kaminsky, 2000).

In contrast to styrene or methyl methacrylate, the radical polymerization of propylene did not give any satisfying results. In 1954, Giulo Natta observed for the first time the polymerization of a stereoregular PP using catalysts based on titanium tetrachloride, which was the first generation of Ziegler Natta catalysts, the mechanisms of which are represented in Scheme 14.1. 


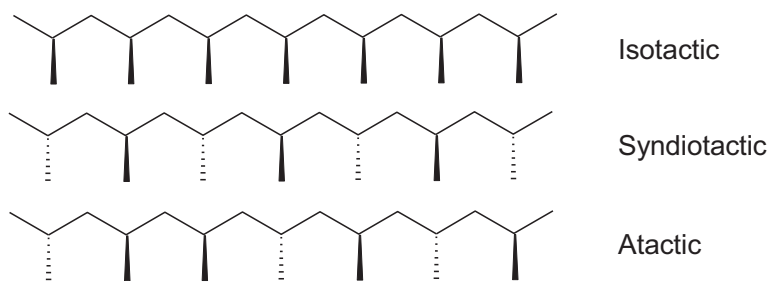

Figure 14.1 Stereoisomer of polypropylene.

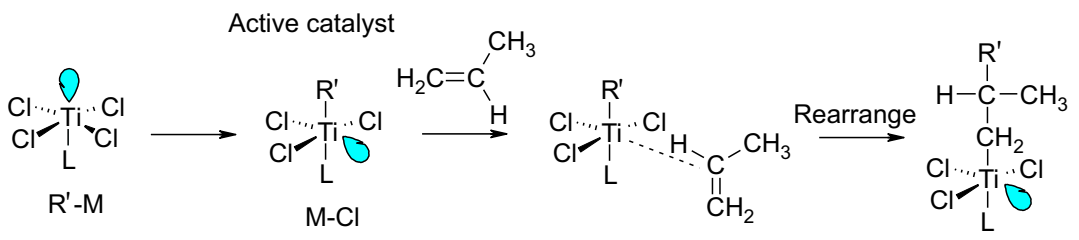

Final product<smiles>[R]C(C)(CC)[Te](Cl)(Cl)(Cl)(Cl)Cl</smiles><smiles></smiles>

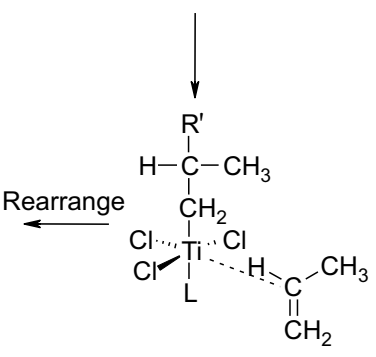

Scheme 14.1 Mechanism of Ziegler Natta polymerization.

The stereoregularity reached almost $80 \%$. It was the beginning of the PP success story. By using Vanadium tetrachloride-based catalysts (typically $\mathrm{VCl}_{4}$ /anisole/ $\mathrm{AlR}_{2} \mathrm{Cl}$ ), syndiotactic PP was obtained (Zambelli and NattaI Pasquon, 1963; De Rosa and Auriemma, 2006).

Latter, second-generation $\mathrm{ZN}$ catalysts were introduced $\left(\mathrm{TiCl}_{4} / \mathrm{Al}\left(\mathrm{C}_{2} \mathrm{H}_{5}\right)_{3} / \mathrm{MgCl}_{2}\right)$ and allowed a high stereoselectivity to be reached $(\mathrm{mm}>97 \%)$ with a yield c.40,000 $\mathrm{g}_{\mathrm{PP}} /\left(\mathrm{g}_{\mathrm{Ti}} \cdot \mathrm{h}\right.$ ) (Huang and Rempel, 1995). Third-generation catalysts are designed to work in propylene solution (Unipol process) or gas phase (Spheripol process) and are the most used for PP synthesis today.

In the 1980s, Kaminsky and coworkers discovered catalysts based on metallocene compounds and methylaluminoxane, which is obtained from the reaction of water with trimethylaluminium $\left(\mathrm{Al}\left(\mathrm{CH}_{3}\right)_{3}\right)($ Kaminsky, 2000). Their activity can reach c. 100,000 $\mathrm{g}_{\mathrm{PP}} /\left(\mathrm{mmol}_{\mathrm{Zr}} \cdot \mathrm{h}\right)$ (Huang and Rempel, 1995). The polymerization mechanism is given in Scheme 14.2.

The Ziegler Natta catalysts have several active sites. Accordingly, the $\mathrm{ZN}$ isotactic PP is characterized by a relatively broad polydispersity index (5-10) (Harding and van Reenen, 2011; Zhang et al., 2011). A narrow molecular weight distribution is a unique feature of polymer products of homogeneous single site metallocene-based catalysts. 


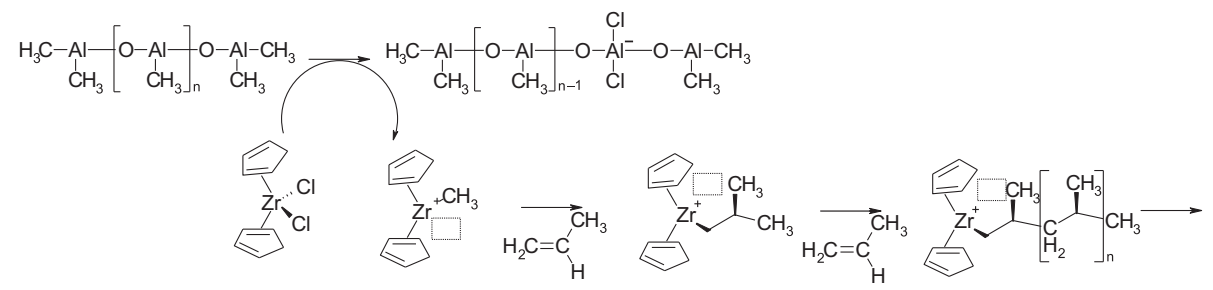

Scheme 14.2 Metallocene polymerization.

Typical values of $\mathrm{M}_{\mathrm{W}} / \mathrm{M}_{\mathrm{N}}$ are 1.9-2.6 for polypropylenes (Huang and Rempel, 1995; Franceschini et al., 2003).

The PP amorphous phase is characterized by a glass transition temperature close to $0^{\circ} \mathrm{C}$ (Aguilar et al., 2003; Zhongde et al., 1985; Chen et al., 2005; Varma-Nair and Agarwal, 2000; Zhang and Cameron, 1999; Arranz-Andrés et al., 2005; Schwarz et al., 2001). Its density is ca 0.85-0.86 (Myers and Mark, 1999; Howe and Mark, 1999). The molar mass between entanglements is about $3.5 \mathrm{~kg} / \mathrm{mol}$ (Van Krevelen, 1990) for isotactic PP and 3.5-4.6 (Fetters et al., 2007) for atactic PP.

Atactic polypropylene cannot crystallize and behaves like a kind of unvulcanized rubber. Only stereoregular forms (syndiotactic and isotactic PP, see Fig. 14.1) are able to crystallize and have interesting mechanical properties. The semicrystalline structure is very complex and depends strongly on thermal history and processing conditions.

Isotactic PP is, by far, the most commonly used stereoisomer. The equilibrium chain configuration is a helix having a period of three monomer units (chiral $3_{1}$ helix). i-PP is able to crystallize into three distinct forms differing in their packing mode: monoclinic $\alpha$-form, hexagonal $\beta$-form, orthorhombic $\gamma$-form, and the smectic mesophase (Table 14.1).

$\alpha$-phase is the most stable and the best known. The crystals are monoclinic. The melting heat $\Delta \mathrm{H}_{\mathrm{M}}$ of the $100 \% \propto$-crystalline phase is given with some scatter in the literature, but the most frequently retained value is $209 \mathrm{~kJ} / \mathrm{kg}$ (Van Krevelen, 1990). The equilibrium melting temperature is ca $208^{\circ} \mathrm{C}$ (Fatou, 1971) but the common melting temperature is usually observed towards $165^{\circ} \mathrm{C}$.

Table 14.1 Parameters of the various PP crystalline forms

\begin{tabular}{|l|l|l|l|l|l|l|l|}
\hline $\begin{array}{l}\text { Crystalline } \\
\text { system }\end{array}$ & $\begin{array}{l}\mathbf{a}(\mathbf{n m}) \\
\mathbf{\alpha} \text { form }\end{array}$ & $\begin{array}{l}\mathbf{b} \\
(\mathbf{n m})\end{array}$ & $\begin{array}{l}\mathbf{c} \\
(\mathbf{n m})\end{array}$ & $\begin{array}{l}\boldsymbol{\alpha} \\
(\text { degrees) }\end{array}$ & $\begin{array}{l}\boldsymbol{\beta} \\
\text { (degrees) }\end{array}$ & $\begin{array}{l}\gamma \\
\text { (degrees) }\end{array}$ & Density \\
$\beta$ form & 0.66 & 2.1 & 0.65 & 90 & 99 & 90 & $0.932-0.943$ \\
$\gamma$ form & 1.9 & 1.9 & 0.65 & 90 & 90 & 120 & 0.92 \\
& 0.66 & 0.1065 & 0.68 & 89.3 & 102.2 & 99.3 & \\
& 0.654 & 0.213 & 0.65 & 89 & 99.6 & 99 & \\
\hline
\end{tabular}


$\beta$-phase is metastable and the crystals are pseudohexagonal. $\beta$-phase growth is faster than the $\alpha$ one, but nucleates more slowly (Varga, 1992). It is thus generated by addition of specific nucleating agents (Libster et al., 2007; Varga et al., 1999). The $\alpha$-phase is generally more brittle than the $\beta$ one (Aboulfaraj et al., 1995) so that the presence of the latter in PP homopolymer generally increases ductility in the finished parts (Chen et al., 2002). Both melting temperature ( $T_{\mathrm{m} \alpha}$ ca 165 vs. $\mathrm{T}_{\mathrm{m} \beta}$ ca $145^{\circ} \mathrm{C}$ (Varga et al., 1999; Shi et al., 1984)) and melting enthalpy (e.g., $\Delta \mathrm{H}_{\alpha}=221 \mathrm{~J} / \mathrm{g}$ vs. $\Delta \mathrm{H}_{\beta}=192 \mathrm{~J} / \mathrm{g}$ (Shi et al., 1984)) are lower than for $\alpha$-phase (see also (Li et al., 1999; Varga, 1992)).

$\gamma$-phase is metastable with triclinic (or orthorhombic) crystals. This phase appears mainly in low-molecular-weight polypropylene by crystallization at very high pressure (Shavit-Hadar et al., 2007) or when propylene is copolymerized with low contents of other olefins (e.g., ethylene or butene) (Turner-Jones, 1971). This polymorph is rather unusual, containing layers of nonparallel chain segments (Meille et al., 1990). Its melting temperature would be lower than $\alpha$-phase $\left(125-150^{\circ} \mathrm{C}\right.$ ) (Marigo et al., 1989; Sowinski et al., 2016).

Smectic (or mesomorphic) phase comes from either the quenching of PP from the molten state (Miller, 1960) or the shear stress of hexagonal crystals (Lezak et al., 2006). Its density is lower than those of the other crystalline phases (0.916). It converts to stable $\alpha$-phase when heated to a temperature ca $100^{\circ} \mathrm{C}$ with a very low exothermal transition (Osawa and Porter, 1994; Cao and Sbarski, 2006; Fichera and Zannetti, 1975; De Santis et al., 2007).

In the specific case of isotactic polypropylene, the morphology is complex: in a given range of temperature of crystallization, two kinds of supermolecular structures usually coexist: the monoclinic $\alpha$ spherulites and the hexagonal $\beta$ ones (Coulon et al., 1999). Coulon et al. (1999) noticed that the $\alpha$ spherulites are brittle while the $\beta$ spherulites are ductile up to large strains. Shish kebabs are induced by an external flow field and consist of fibrous shish aligned along the extension/flow direction with lamellae (kebabs) nucleated by the surface of the shish (Balzano et al., 2016).

Syndiotactic PP also displays a very polymorphic behavior. The most stable form (form II) can be obtained in oriented stretched fibers. Its crystal structure and unit cell geometry was proposed to be orthorhombic with $\mathrm{a}=1.45 \mathrm{~nm}, \mathrm{~b}=0.58 \mathrm{~nm}$, and $\mathrm{c}=0.56 \mathrm{~nm}$ and space group C222 ${ }_{1}$ (Corradini et al., 1967). The equilibrium melting temperature of crystalline syndiotactic $\mathrm{PP}$ (with $94 \%$ racemic diads) with a sufficiently high molar mass $(>40,000 \mathrm{~g} / \mathrm{mol})$ is about $160^{\circ} \mathrm{C}$ (Rodriguez-Arnold et al., 1994) but could reach about $180^{\circ} \mathrm{C}$ (De Rosa et al., 1998) and an equilibrium heat of fusion ranging from 183 to $197 \mathrm{~J} / \mathrm{g}$ (Rodriguez-Arnold et al., 1994). The common melting temperature of a syndiotactic PP is ca $130^{\circ} \mathrm{C}$ (Zou et al., 2007; Zhang et al., 2005).

The PP solubility parameter is rather low (Safa et al., 2008; Bond and Spruiell, 2001a). Its apolar character makes PP hydrophobic (water equilibrium concentration lower than $0.1 \%$ ), not easily wettable or dyeable. In contrast, it is easily washable. The surface polarity can be improved by a wide variety of treatments generally consisting in superficial oxidation (Stakne et al., 2003) or plasma treatment (Wei et al., 2005; Aouinti et al., 2003). 
Isotactic and syndiotactic PP are insoluble in most common organic solvents. They can however become soluble in aromatic solvents at temperatures close to the melting point of the crystalline phase. This is typically helpful for molar mass measurement purposes by Gel Permeation Chromatography. In that case, the average molar masses are estimated from a calibration using polystyrene standards having a polydispersity index $=1$, and corrected using the Universal Calibration Method:

$$
\ln \mathrm{M}_{\mathrm{PP}}=\frac{1}{1+\alpha_{\mathrm{PP}}} \cdot \ln \left(\frac{\mathrm{k}_{\mathrm{PS}}}{\mathrm{k}_{\mathrm{PP}}}\right)+\frac{1+\alpha_{\mathrm{PS}}}{1+\alpha_{\mathrm{PP}}} \cdot \ln \mathrm{M}_{\mathrm{PS}}
$$

$\mathrm{k}_{\mathrm{PP}}, \mathrm{k}_{\mathrm{PS}}, \alpha_{\mathrm{PP}}$, and $\alpha_{\mathrm{PS}}$ are the Mark Houwink constants. The values to be used must have been measured at the same temperature in the same solvent. Typical values for the classical GPC solvent (1,2,4 trichlorobenzene at temperatures ranging for $135-150^{\circ} \mathrm{C}$ ) are given in the following table (http://www.ampolymer.com/; Evans, 1973) (Table 14.2).

Due to its hydrocarbon structure, especially the presence of a tertiary $\mathrm{C}-\mathrm{H}$ bond, PP is relatively sensitive to thermal and photochemical oxidation. It cannot be processed, stored, or used without stabilizers (Schwarzenbach et al., 2000) as it will be detailed in the following.

\subsection{Polypropylene fiber processing}

\subsubsection{Overview of the process}

Different methods of PP fiber extrusion include gel spinning (Cannon, 1982), electrostatic (Larrondo, 1981) or electro spinning (for some PP-based materials (Berber et al., 2016)), and melt spinning. Melt spinning is a common method in which fibers are extruded through a die and then drawn (Gupta et al., 1997). This is, by far, the most used technique for manufacturing PP fibers at industrial scale. It is very cost effective, no solvent or washing is required, and very high spinning rate can be reached. It is the preferred method of production of polymers that will not suffer thermal degradation at the temperatures required to form a melt solution of the desired viscosity.

The melt spinning process can be summarized as follows:

- Polymer granules are melted and then extruded through the spin head. Typical processing temperatures range from 210 to $280^{\circ} \mathrm{C}$ (Horrocks et al., 1994; Lu and Spruiell, 1987a; Andreassen et al., 1994).

- The metering pump controls the flow of molten liquid to the spin pack, composed of filters and channels supplying molten polymer to a multifilament spinneret.

- The quench air (temperatures of around $30^{\circ} \mathrm{C}$ are reported (Kohler and $\mathrm{McHugh}, 2007$ )) cools the fibers as they emerge.

Two melt-spinning processes can be distinguished, depending on crystallization rate:

1. Short spinning (also named compact spinning) characterized by a high velocity of cooling air, a low spinning velocity, and a low draw down ratio. It corresponds thus to a fast 
Table 14.2 Mark Houwink constants for i-PP, s-PP, and PS for typical GPC conditions (De Rosa and Auriemma, 2006; http://www.ampolymer.com/; Evans, 1973)

\begin{tabular}{|l|l|l|l|l|l|l|l|}
\hline $\mathbf{T}\left({ }^{\circ} \mathbf{C}\right)$ & Solvent & $\mathbf{k}_{\mathbf{P S}}$ & $\boldsymbol{\alpha}_{\mathbf{P S}}$ & $\mathbf{k}_{\mathbf{P P}}$ & $\boldsymbol{\alpha}_{\mathbf{P P}}$ & References & $\mathbf{R e m a r k}$ \\
\hline 145 & TCB & & & 0.000137 & 0.75 & http://www.ampolymer.com/ \\
145 & TCB & 0.000121 & 0.707 & 0.000156 & 0.76 & http://www.ampolymer.com/ \\
135 & TCB & 0.000161 & 0.677 & 0.0000834 & 0.8 & http://www.ampolymer.com/ \\
135 & ODCB & 0.000138 & 0.7 & 0.00013 & 0.78 & Evans (1973) \\
135 & TCB & & & 0.000166 & 0.733 & De Rosa and Auriemma (2006) \\
135 & TCB & & & 0.000288 & 0.733 & De Rosa and Auriemma (2006) & i-PP \\
\hline
\end{tabular}


crystallization. In short spinning, there are three stages: spinning, drawing, and annealing at a temperature close to the melting temperature (Kohler and McHugh, 2007). The take up velocity (or spinning velocity) is higher than $750 \mathrm{~m} / \mathrm{min}$ (up to 3000) (Gupta et al., 1997; Kohler and McHugh, 2007)). The drawing is mostly performed in the solid state. Fibers are characterized by their

a. draw down ratio (for the spinning stage), which is the ratio of spinning velocity to extrusion velocity, and can range from 20 to 4000 (Andreassen et al., 1994; Choi and White, 2004);

b. draw ratio (for the drawing stage), which is the ratio of output velocity to input velocity, and can range from 1.2 to ca 6.5 (Gupta et al., 1997; Andreassen et al., 1994; Kang et al., 2011). At higher draw ratios, defects and possibly voids can be observed (El Maaty et al., 1996);

c. annealing ratio (for the annealing stage), which is the ratio: (input velocity-output velocity)/input velocity, and can range from $2 \%$ to $7 \%$ (Andreassen et al., 1994).

Typical fibers produced by this process have tensile moduli in the range 0.5-3.0 GPa, tensile strengths in the range 50-600 MPa, and elongations at break in the range 50\%-600\% (Andreassen et al., 1994).

2. Long spinning (also named conventional spinning) is on the contrary characterized by a relatively slow crystallization. In long spinning, drawing is mostly possible from the molten state. The usual take up velocities are of the order of $5000-6000 \mathrm{~m} / \mathrm{min}$.

The final products are nonwoven fibers such as

- staple fibers,

- spunbonded (spunlaid) with diameter ranging from 10 to $30 \mu \mathrm{m}$,

- monofilament yarns (for ropes and woven fabrics),

- meltblown $=$ diameter $<10 \mu \mathrm{m}$ (filtration). Melt blowing is a special form of melt spinning process, which produces very fine but weak fibers that are useful for filters and other applications where high surface area is important and strength is a secondary factor.

\subsubsection{Process variables}

The main process variables are

- The take-up velocity: it was shown that an increase in spinning speed results in an increase in molecular orientation and in stress-enhanced crystallization.

- The extrusion temperature: when lowering the process temperature, the possible processinduced degradation is decreased. Moreover, a lower temperature induces a higher viscosity and thus a higher stress in the spinline leading to an increased molecular orientation and subsequent crystallization (Andreassen et al., 1994).

- the mass throughput: there is an optimum between the mass throughput and the crystallization: an increase of mass throughput leads to a decrease of the stress in the spinline (unfavorable to crystallization), together with a decrease in the cooling rate (which is favorable to the crystallization process).

- The cooling temperature: a lower temperature of cooling air causes the crystallization to occur closer to the spinneret, and then an increase in the stresses in the spinline. However, it also induces a possible breakage of the fibers or the quenching and the formation of the smectic phase under an extra rapid cooling condition (Kang et al., 2011) instead of the 
Table 14.3 Main mechanical properties of the i-PP fibers with different crystal forms (Cao and Sbarski, 2006)

\begin{tabular}{|l|l|l|}
\hline \multirow{2}{*}{ Property } & \multicolumn{2}{|c|}{ Crystal form } \\
\cline { 2 - 3 } Tensile modulus (MPa) & Monoclinic & Mesomorphic \\
Elongation at break (\%) & 1570 & 1120 \\
\hline
\end{tabular}

"regular" $\alpha$-monoclinic phase (under normal cooling conditions) (Cao and Sbarski, 2006) with a certain impact on the fiber mechanical properties (Table 14.3). However, a thermal annealing allows the monoclinic phase to be recovered (Cao and Sbarski, 2006; Osawa and Porter, 1994; Fichera and Zannetti, 1975; El Maaty et al., 1996).

\subsubsection{Materials variables}

It is noteworthy that, compared to classical polar fiber-forming polymers such as polyamides or PET, PP must have higher average molar mass (typically $\mathrm{M}_{\mathrm{W}}>100 \mathrm{~kg} / \mathrm{mol}$ ) in order to have good mechanical properties (see below). As a result, PP is more viscoelastic than polyamides and PET in the molten state, and that brings both advantages and drawbacks. The advantage is that it is the viscoelastic behavior that allows fibers of very small diameter (few micrometers) to be obtained at very high rate. The drawback is that viscoelasticity is responsible for shear rate dependence, eventually die resonance, e.g., a periodic diameter fluctuation, and melt fracture above a critical shear rate. These defects can be avoided with a rigorous control of rheological properties, which is only possible with a no less rigorous control of Molecular Weight Distribution (MWD).

Melt spinning of polypropylene is done, almost exclusively, with the semicrystalline isotactic form. It requires a relatively low viscosity e.g., a melt index typically higher than $4 \mathrm{~g} / 10 \mathrm{~min}$ (and up to $300 \mathrm{~g} / 10 \mathrm{~min}$ ) (Horrocks et al., 1994; Choi and White, 2004; Kang et al., 2011; El Maaty et al., 1996; Lu and Spruiell, 1987b).

Since it was observed that PP grades characterized by a broad molar weight distribution could not be spun without breaking (Lu and Spruiell, 1987b), classical ZieglerNatta PP grades cannot be processed at high spinning rates due to their wide MWD. In the 1980s, polymers with sharper MWD were obtained using controlled peroxideinitiated thermal degradation (Kalantari et al., 2007). At the end of the 20th century, metallocene catalysis allowed the polymer polydispersity to be controlled during its synthesis leading to an increase in spinning rates and in fiber toughness (Bond and Spruiell, 2001b,c). Higher tenacities, with consequent lower percent elongation to break, could be achieved by spinning the narrow MWD polymers at high spinning speeds (Lu and Spruiell, 1987b). The yield strain was also observed to be higher for a metallocene than a Ziegler Natta of comparable viscosity (Sakurai et al., 2005). This effect was associated with the development of higher birefringence in these samples (Lu and Spruiell, 1987b). 


\subsection{Initial tensile properties}

Usually, mechanical properties of fibers are evaluated by tensile testing. From this test, different mechanical properties can be assessed: Young modulus, stress at yield, and strain at break. Typical values (Uehara et al., 1996), depending on draw ratio, are given in Table 14.4:

These properties depend on the temperature and deformation rate used for the test, PP molar mass, chain orientation, and crystalline morphology. The latter characteristics are strongly dependent on the processing conditions (De Rovère et al., 2000). As it has been previously shown, there are several processing methods: gravity spinning, melt spinning, and melt blowing. Furthermore, for each process, different parameter values such as temperature, pressure, extrusion rate, and draw ratio lead to different crystalline morphologies.

\subsubsection{Stress-strain curve}

In order to illustrate the mechanical behavior of PP fibers, a stress-strain curve is shown in Fig. 14.2. This curve characterizes the mechanical behavior of a PP geotextile fiber having a diameter close to $30 \mu \mathrm{m}$ loaded at a constant crosshead displacement rate at $50 \mathrm{~mm} / \mathrm{min}$ and using a $100 \mathrm{~N}$ load cell. In the same manner as for isotropic PP samples, the initial part of the curve exhibits a pseudolinear behavior followed by a yield. This yield corresponds to the beginning of plastic deformation associated with a necking process. The necking process is often more diffuse than in isotropic PP samples so that no knee can be observed on the stress-strain curve. In this case, yield stress $\left(\sigma_{\mathrm{y}}\right)$ value can be defined as the beginning of nonlinear behavior.

\subsubsection{Mechanical properties}

Compared to isotropic i-PP samples, fibers exhibit higher Young's moduli (E) and yield stresses $\left(\sigma_{\mathrm{y}}\right)$ but lower strains at break $\left(\varepsilon_{\mathrm{R}}\right)$. However, depending on processing methods and conditions, Young's moduli of PP fibers can be quite different. For

\section{Table 14.4 Tensile properties as a function of draw ratio for iPP and sPP having similar molar masses (Uehara et al., 1996)}

\begin{tabular}{|l|l|l|l|l|l|l|}
\hline & \multicolumn{2}{|c|}{$\begin{array}{c}\text { Tensile modulus } \\
\text { (GPa) }\end{array}$} & \multicolumn{2}{c|}{$\begin{array}{c}\text { Tensile strength } \\
\text { (GPa) }\end{array}$} & \multicolumn{2}{c|}{$\begin{array}{c}\text { Strain at break } \\
(\%)\end{array}$} \\
\cline { 2 - 7 } & iPP & sPP & iPP & sPP & iPP & sPP \\
\hline Draw ratio $\lambda=4$ & 3 & 0.8 & 200 & 130 & 150 & 100 \\
Draw ratio $\lambda=7$ & 6 & 1.7 & 400 & 280 & 50 & 50 \\
Draw ratio $\lambda=10$ & 15.5 & $*$ & 600 & $*$ & 20 & 50 \\
\hline
\end{tabular}




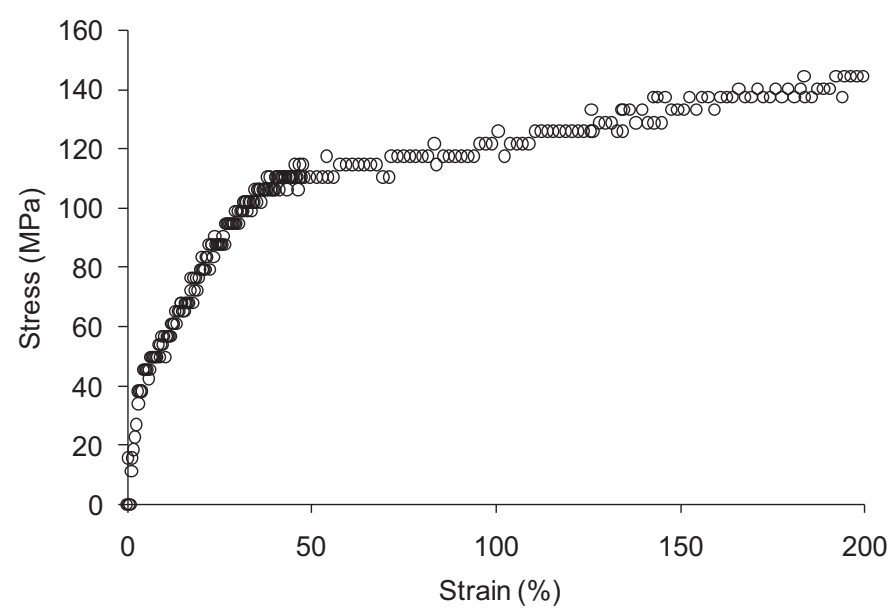

Figure 14.2 Typical stress-strain curve for a PP fiber obtained by melt spinning (diameter of $30 \mu \mathrm{m})$.

instance, the methods based on melt spinning and drawing under particular conditions (slow stretching on a tensile testing machine or in an oven) lead to elastic modulus values in the range from 10 to $22 \mathrm{GPa}$, whereas, by using solid state extrusion (hydrostatic extrusion, die drawing followed by slow stretching or spinline stress), elastic modulus values range from 17 to $20 \mathrm{GPa}$ (Gregor-Svetec and Sluga, 2005).

This increase of modulus is often attributed to a specific oriented morphology called shish-kebab. Indeed, for the melt-spinning process for instance, macromolecules are highly extended prior to crystallization and the latter, when it occurs, does not change the macromolecular orientation. Under these conditions, lamellar surfaces would be normal to the fiber direction leading to high modulus. According to this, many modeling approaches have been proposed to relate elastic properties of crystalline phase to elastic modulus of PP fibers (Hadley et al., 1997). Crystalline phase and orientation degree are responsible for yield stress increase; typically its value can reach up to $100 \mathrm{MPa}$ compared to $27 \mathrm{MPa}$ for isotropic i-PP.

Concerning Ultra-High-Molecular-Weight PP, a maximum modulus value of $40.4 \mathrm{GPa}$ has been obtained by Matsuo et al. (1986) by using the gel-casting method. This value approaches the theoretical crystal modulus of i-PP (35-42 GPa) (Ikeda and Ohta, 2008).

Finally, fibers of s-PP display a rubberlike mechanical behavior when fibers are subjected to successive elongation and relaxation cycles (Loos and Schimanski, 2000; De Rosa and Auriemma, 2006). This is the most important characteristic and unusual physical property for s-PP fibers. For the latter, the maximum achievable tensile modulus value is much lower than for i-PP, since this latter is characterized by higher crystal modulus, crystallinity ratio, and drawability compared to the former. As a result, the maximum tensile modulus of oriented s-PP is close to $3 \mathrm{GPa}$. 


\subsubsection{Fracture properties}

Fracture properties of i-PP fibers depend on intrinsic parameters such as molar mass, crystallinity ratio, morphology, and orientation. The latter is linked to processing conditions especially draw ratio. This aspect has been extensively studied in the literature (Xu et al., 2003). But these properties are also highly dependent on defects induced by the processing at the surface or in the core of the fiber.

Classically, stress at break is close to $150 \mathrm{MPa}$ and strain at break values range from $150 \%$ to $300 \%$. An annealing process would increase stress at break but decrease strain at break.

On fibers made by melt spinning, it has been observed that strain at break is determined by the spinline stress provided that weight average molecular molar mass is higher than $180 \mathrm{~kg} / \mathrm{mol}$ (Nadella et al., 1977). Below this critical value, the fiber fails in a brittle manner with a strain at break close to $10 \%$ and without strain hardening. Fig. 14.3(a) shows strain at break as a function of weight average molar mass for fibers having different molar masses: below $150 \mathrm{~kg} / \mathrm{mol}$, fibers are brittle. It is noteworthy that a molar mass decrease is always accompanied by a crystallinity ratio increase (Fig. 14.3(b)) (Fayolle et al., 2008a).

Fracture properties, i.e., stress and strain and break, are often interpreted by using the tie molecule concept. Indeed, it has been common to consider that the fiber structure is based on "microfibrils" or "nanofibrils." These fibrils are formed from shishkebab structures as previously seen. In order to obtain good fracture properties, the crystalline regions have to be interconnected by chains or entangled chains through an amorphous region, called "tie-molecules" (Seguela, 2005). In the case of meltspinning fibers, one can assume that a lack of interconnections is responsible for brittle failure below the critical molar mass close to $150 \mathrm{~kg} / \mathrm{mol}$.

(a)

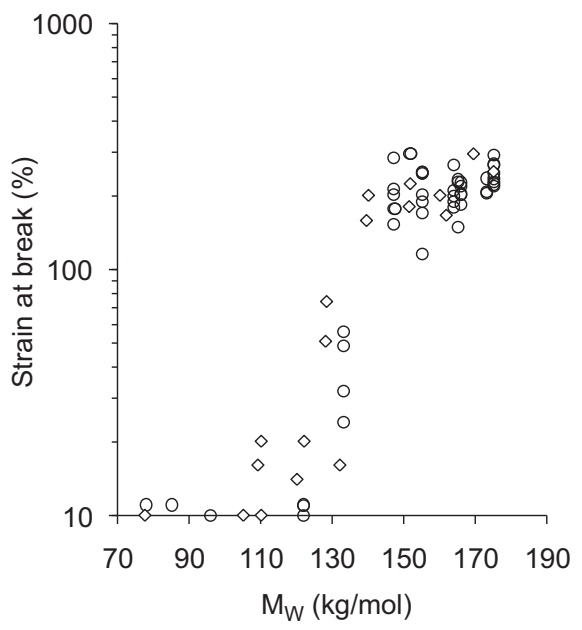

(b)

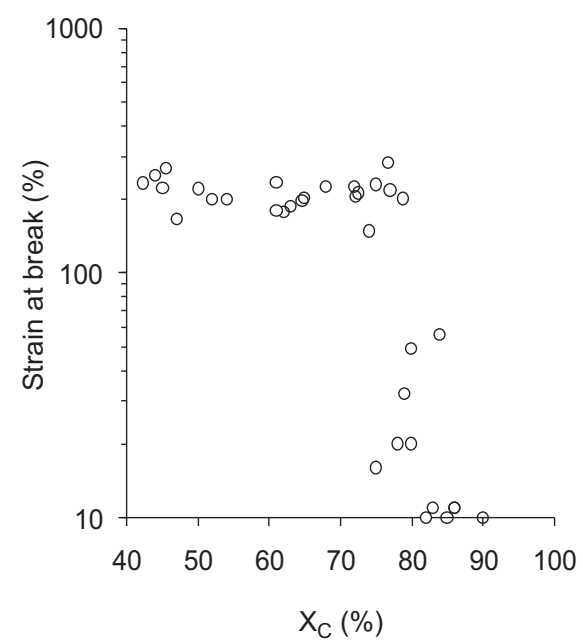

Figure 14.3 Strain at break as a function of weight average molar mass $M_{W}$ (a) and as a function of crystallinity ratio $\mathrm{X}_{\mathrm{C}}(\mathrm{b})$. 


\subsection{Fiber durability}

\subsubsection{Failure processes}

Fiber failure can result from mechanical loading, from physical polymer-solvent interactions, or from chemical interaction between the polymer and reactive species (water, oxygen, etc.) present in the environment, or from a combination of these mechanisms.

Mechanical failure can result from creep, fatigue, or accidental overloading resulting for instance from earthquake in the case of geotextiles. Efficient rules for mechanical design are in principle available (Kongkitkul and Tatsuoka, 2007; Paulsen and Kramer, 2004; Kucher et al., 2007) to avoid anomalous mechanical failure.

Polymer-solvent physical interactions can considerably reduce the time to failure when the material is subjected, at the same time, to mechanical loadings (Ward et al., 2001). In the case of PP, however, polymer-solvent interactions are strongly limited by the nonpolar character of the polymer and by its crystallinity. It is well known that PP is soluble only at high temperature, practically in the molten state, in a small number of aromatic solvents. PP fibers cannot be recommended in applications where they are subjected to mechanical loading in the presence of aromatic chlorinated solvents.

Chemical interactions between PP and reactive species present in the environment are strongly dependent on the hydrocarbon structure of the polymer. This type of structure is totally unreactive with water and with most of the water-soluble species: acids, bases, salts, except the case of oxidizing ones such as nitric acids, potassium permanganate, hydrogen peroxide, etc.

Thus the only significant ageing process in PP is oxidation with the above mentioned reactants, or simply with atmospheric oxygen. The rest of this section will therefore be devoted to oxidation and its consequences on mechanical behavior of PP fibers.

\subsubsection{Oxidation mechanism}

After the pioneering works of Semenov in the former USSR (Emanuel and Buchachenko, 1987) and Bolland and coworkers in England (Bolland and Gee, 1946a, 1946b), it was widely recognized that oxidation occurs through a radical chain mechanism of which the main peculiarity is that it generates hydroperoxides $(\mathrm{POOH})$ that decompose easily to give new radicals inducing thus a catastrophic autoacceleration of the reaction. The propagation of the radical chain involves two steps: first the oxygen addition to an alkyl radical $\left(\mathrm{P}^{\circ}\right)$ to give a peroxy radical $\left(\mathrm{POO}^{\circ}\right)$ and second the abstraction of hydrogen belonging to the substrate to give hydroperoxide ( $\mathrm{POOH})$ and a new alkyl radical. The second step is at least one million times slower than the first one so that it plays a key role in the oxidation kinetics.

The $\mathrm{PP}$ monomer units contain a tertiary $\mathrm{C}-\mathrm{H}$ bond especially reactive in hydrogen abstraction processes that partially explains the relatively high sensitivity of the polymer to oxidation. Another very important characteristic of PP oxidation is that termination by a bimolecular combination of peroxy radicals is not very efficient, which contributes to increase the oxidizability of the polymer. 
Hydroperoxide decomposition can be unimolecular (1u) or bimolecular (1b) and catalyzed by transition metals ( $\mathrm{Ti}, \mathrm{Cu}, \mathrm{Fe}, \mathrm{Cr}, \mathrm{Co}$, etc.) (Gugumus, 2000). In all cases, it produces alkoxy radicals of which the peculiarity is to rearrange mostly by $\beta$-scission (see Scheme 14.3).

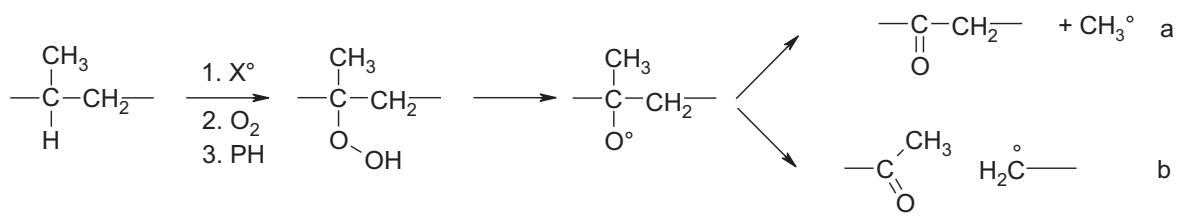

Scheme 14.3 Summary of the PP oxidation mechanism leading to carbonyls (a \& b) and scissions (b).

As will be shown below, chain scission is the direct cause of embrittlement. Finally, most of the important features of PP oxidation can be well predicted from a standard mechanistic scheme where $\mathrm{P}=\mathrm{O}$ are carbonyls, $\mathrm{s}$ are chain scissions, and $\mathrm{P}^{\circ}, \mathrm{POO}^{\circ}$, $\mathrm{POOH}$ are defined above:

$$
\begin{array}{ccc}
\text { (1u) } & \mathrm{POOH} \rightarrow 2 \mathrm{P}^{\circ}+\mathrm{P}=\mathrm{O}+\mathrm{s} & \mathrm{k}_{1 \mathrm{u}} \\
\text { (1b) } & 2 \mathrm{POOH} \rightarrow \mathrm{P}^{\circ}+\mathrm{POO}^{\circ}+\mathrm{P}=\mathrm{O}+\mathrm{s} & \mathrm{k}_{1 \mathrm{~b}} \\
\text { (2) } & \mathrm{P}^{\circ}+\mathrm{O}_{2} \rightarrow \mathrm{POO}^{\circ} & \mathrm{k}_{2} \\
\text { (3) } & \mathrm{POO}^{\circ}+\mathrm{PH} \rightarrow \mathrm{POOH}+\mathrm{P}^{\circ} & \mathrm{k}_{3} \\
\text { (4) } & \mathrm{P}^{\circ}+\mathrm{P}^{\circ} \rightarrow \text { inactive products } & \mathrm{k}_{4} \\
\text { (5) } & \mathrm{P}^{\circ}+\mathrm{POO}^{\circ} \rightarrow \text { inactive products } & \mathrm{k}_{5} \\
\text { (6) } & \mathrm{POO}^{\circ}+\mathrm{POO}^{\circ} \rightarrow \text { inactive products } & \mathrm{k}_{6}
\end{array}
$$

The kinetic behavior depends essentially on the initiation mode as illustrated by Fig. 14.4.

In the case of radiochemical ageing at relatively high dose rate, initiation results essentially from polymer radiolysis and hydroperoxide decomposition can be neglected for short exposure times at low temperatures. In this case, oxidation proceeds at a constant rate. Even if, in the absence of oxygen, crosslinking coexists with chain scissions (Black and Lyons, 1957), the latter becomes totally predominant for $\gamma$-irradiation in air (Decker and Mayo, 1973; Tidjani and Watanabe, 1996).

In the case of thermal ageing at low temperature, since $\mathrm{k}_{1 \mathrm{u}}$ is relatively low, the hydroperoxide concentration reaches rapidly a level where bimolecular decomposition becomes predominant. In this case, oxidation kinetics displays an induction period followed by a catastrophic autoacceleration. Whatever the chosen end of life criterion, lifetime is always of the order of the induction time. 


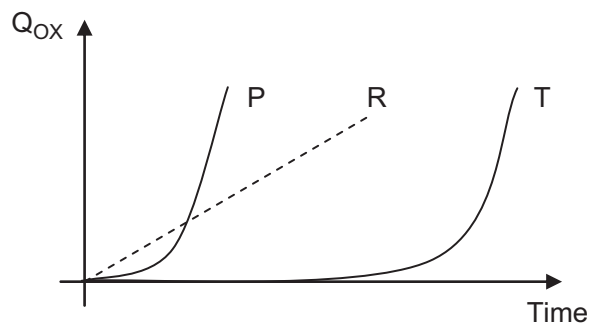

Figure 14.4 Shape of oxidation kinetic curves (for instance Qox is the quantity of absorbed oxygen) in the case of radiochemical (R), photochemical (P), and thermal (T) oxidation at low temperature typically in solid state.

In the case of photochemical ageing, with the commonly used light intensities

- carbonyls undergo Norrish I or Norrish II processes leading to chain scissions;

- hydroperoxides react by the unimolecular mechanism with a $\mathrm{k}_{1 \mathrm{u}}$ value several orders of magnitude higher than for thermal ageing at the same temperature.

Those processes were quantified by François-Heude et al. (2014) who first proposed an analytical equation for describing the induction time as a function of light and temperature. The direct ultraviolet initiation corresponding to carbonyls and hydroperoxides decomposition as a function of UV intensity and wavelength was added, as supplementary reactions in the kinetic model presented above, so as to describe the photothermal degradation of unstabilized PP for a wide range of temperature and UV intensities (François-Heude et al., 2015).

As a result, the induction time is reduced to zero and autoacceleration is considerably less marked than for thermal ageing.

\subsubsection{Oxidation-induced embrittlement}

Embrittlement due to oxidative ageing results from the fact that the polymer loses its capacity to undergo plastic deformations. It occurs suddenly, indicating the existence of a critical state separating ductile and brittle regimes of deformation. The most probable causal chain can be ascribed as follows: Oxidation $\rightarrow$ chain scission in amorphous phase $\rightarrow$ molar mass decrease $\rightarrow$ easier chain disentanglements $\rightarrow$ chemical crystallization $\rightarrow$ embrittlement.

At the present state of our knowledge, it is difficult to choose between two embrittlement mechanisms: a purely micromechanical one in which the key factor would be a critical interlamellar distance $l_{a}$ or a molecular mechanism in which the key factor would be critical concentration of tie chains interconnecting crystalline lamellae (Fayolle et al., 2008b). In both cases, however, for a given starting morphology, this critical state corresponds to a critical value of the weight average molar mass: $\mathrm{M}_{\mathrm{W}}=\mathrm{M}_{\mathrm{C}}^{\prime}$. For PP, $\mathrm{M}_{\mathrm{C}}^{\prime}$ is of the order of $200 \mathrm{~kg} / \mathrm{mol}$ for quasiisotropic samples and $130 \mathrm{~kg} / \mathrm{mol}$ for fibers (Fayolle et al., 2008a). In the latter case, oxidized fibers become brittle when the crystallinity ratio reaches $80 \%$. As a result, specific crystalline 
morphology associated to fiber processing conditions will clearly modify the critical state for embrittlement in terms of molar mass and crystallinity compared to nonoriented PP samples.

\subsubsection{Stabilization}

Since oxidation results from a radical chain process with relatively low initial rate and high initial kinetic chain length (number of propagation events per initiation event), it is possible to envisage efficient ways for its inhibition:

1. Radical scavenging (e.g., chain interruption) by aromatic amines, hindered phenols, or hindered amines of the tetramethylpiperidine type (HALS). One of the most widely studied families of antioxidants is based on derivates of 2,6 di-tert-butylphenols. In a first approach, their mechanism of action can be summarized as presented in Scheme 14.4 (Pospísili, 1993a, 1993b; Richaud et al., 2011):

a. they react with a peroxy radical $\left(\mathrm{POO}^{\circ}\right)$ to give a phenoxy $\left(\mathrm{A}^{\circ}\right)$,

b. the phenoxy isomerize and can trap a second peroxy radical.

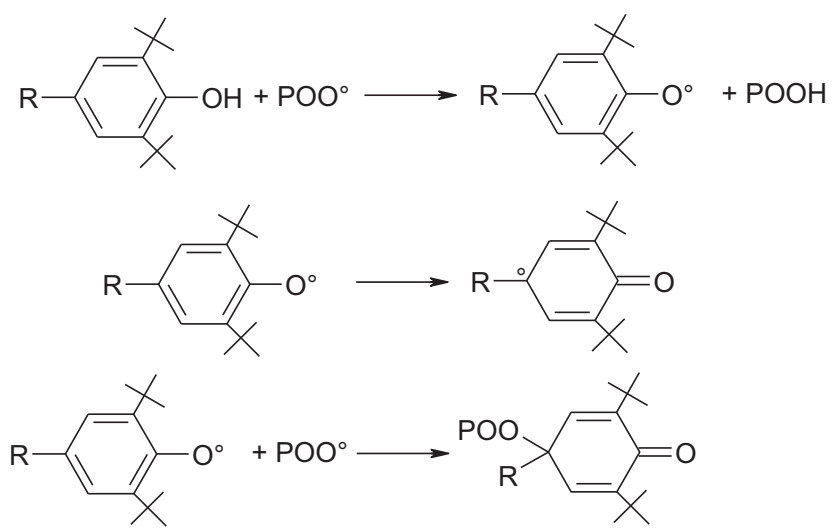

Scheme 14.4 Simplified mechanism of stabilization by phenols.

HALS are derivative of 2,2,6,6 tetramethylpiperidine. They trap radicals by a loop mechanism presented in Scheme 14.5.

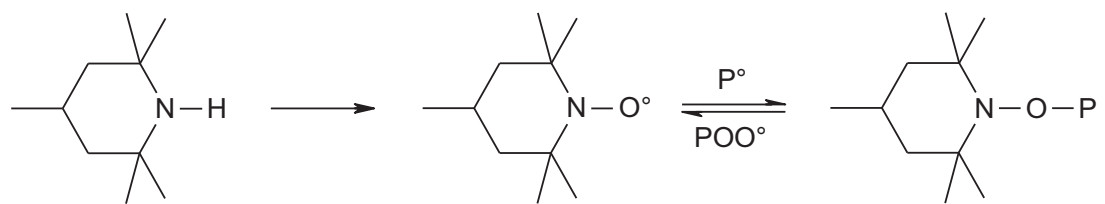

Scheme 14.5 Simplified mechanism of HALS stabilization (Denisov, 1989).

It is noteworthy to highlight that phenols and phosphites are so-called "sacrificial" stabilizers, which are definitively consumed after trapping their target species, whereas HALS regenerate at least as long as $>\mathrm{N}-\mathrm{O}^{\circ}$ and $>\mathrm{N}-\mathrm{OP}$ are not destroyed by side 


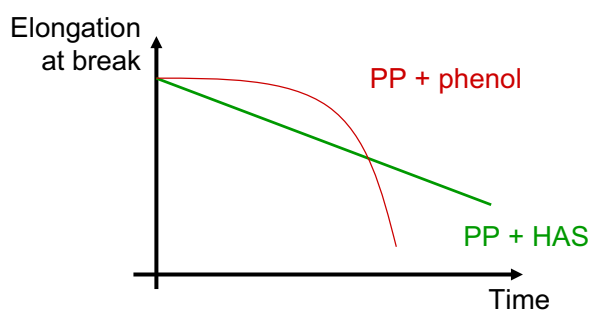

Figure 14.5 Embrittlement mechanism of PP with different stabilizer molecules.

reactions (Haillant and Lemaire, 2006). This regenerative mechanism leads to a very progressive embrittlement process of PP + HALS mixtures in contrast to PP + phenols where the mechanical properties are shown to suddenly drop (Gensler et al., 2000; Fig. 14.5).

2. Decrease the initiation rate by hydroperoxide destruction by a nonradical way, using sulfides or phosphites, and suppression of catalytic effects of metallic impurities using metal chelatants. The most common hydroperoxide reducers are phosphites (Scheme 14.6).

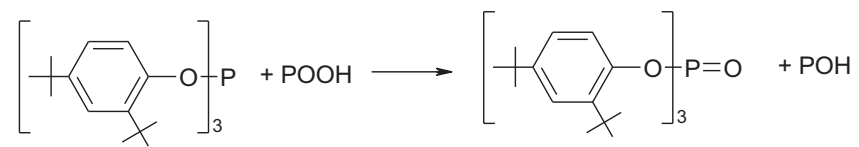

Scheme 14.6 Stabilization by phosphites.

They are very often used in combination with phenols (Horrocks et al., 1994) because of a strong synergistic effect (Verdu et al., 2003).

3. In the specific case of photooxidation: decrease of the photoinitiation rate using UV absorbers (but they are not very efficient in thin samples), pigments such as $\mathrm{TiO}_{2}$ with adequate surface treatments, carbon black (Klemchuk, 1983), or quenchers to deactivate photoexcited states responsible for photoinitiation.

Analysis by isothermal (Mueller et al., 2003; Reano et al., 2016) or nonisothermal (Astruc et al., 2004) differential scanning calorimetry or chemiluminescence (Aratani et al., 2015; Jipa et al., 2000) under oxygen is very often used for checking the initial stabilizer content and comparing the efficiency of stabilizer packages. However, the use of such methods for the quantification of residual stabilizer content in aged materials remains questionable (Richaud, 2013).

\subsubsection{Lifetime prediction methods}

Unstabilized PP cannot be processed or even stored at ambient temperature where its lifetime would not exceed a few years, even in the dark. Considerably longer lifetimes can be obtained with adequately chosen stabilizer systems. For example, lifetimes of the order of 100 years are expected in the case of PP geotextiles. The problem for users 
is to try to determine this lifetime from accelerated ageing tests. Two ways are possible: the empirical way, in which one key condition is taken to be a good simulation of natural ageing conditions, and the scientific way in which the key condition is based on a good scientific model to represent ageing effects. The empirical way has largely predominated in the past half-century, despite its low reliability (Suits and Hsuan, 2003; Li and Hsuan, 2004; Hsuan and Li, 2005; Koerner et al., 1992). The emergence of numerical tools to solve very complex kinetic schemes has recently given an impulsion to the scientific approach (Rincon-Rubio et al., 2001). In this latter case, accelerated ageing tests are not intended to simulate natural ageing but only to identify model parameters. It appears then that tests at variable oxygen pressures (Bajer, 2014; Richaud et al., 2008a), which were rarely used in the past, are likely to distort the degradation mechanism with the appearance of unexpected side reactions (Richaud et al., 2008b), but are especially interesting for the estimation of kinetic parameters (Richaud et al., 2006).

\subsection{Example of PP fiber ropes in service}

In order to illustrate the mechanisms described above, and particularly the oxidative degradation of these fibers when exposed to sunlight, the case of marine ropes will be discussed.

PP fibers, frequently in combination with PE or polyester, are used as a cheaper alternative to polyamide or polyester mooring ropes. They have the additional advantage of floating. Fig. 14.6 shows an example of a 44-mm diameter PP/PE copolymer monofilament rope, with a nominal break load of $320 \mathrm{kN}$.

The fibers are twisted together into rope yarns, these are twisted together into strands, and the strands are either twisted or braided together to make the rope. In the example shown here the construction is an 8-strand braid in a $4 \times 2$ geometry. More details on rope constructions can be found in the work by McKenna et al. (2004). In general, the assembly of the different elements results in a reduction in stiffness and strength compared to the properties of the individual elements. Here the measured rope strength efficiency is about $66 \%$, determined by comparing the nominal break load to the sum of the measured rope yarn strengths.

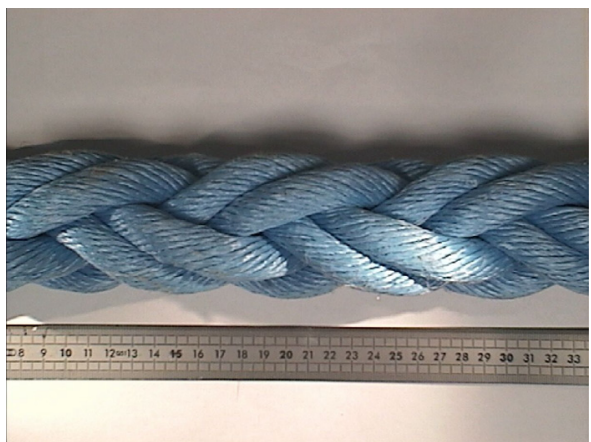

Figure 14.6 PP/PE marine rope. 


\subsubsection{Laboratory aging of rope yarns}

As part of a study to examine the long-term behavior of these materials rope yarns were removed from a new rope of this $4 \times 2$ braided construction and aged in a Sapratin environmental chamber, exposed to radiation from a metal halide lamp with a solar spectrum and a power of $1020 \mathrm{~W} / \mathrm{m}^{2}$. After different exposure periods, samples were removed from the chamber and tested in tension to failure. Fig. 14.7 shows the results. Break stress values are given in N/tex units, with the linear weight of 1 tex defined as $1 \mathrm{~g} / \mathrm{km}$. This avoids having to define a yarn cross-section area.

There is a significant drop in strength after 1 month's exposure. The equivalence between aging in a chamber and aging under real conditions is difficult to evaluate, but in a previous study on sailcloth ageing an accelerating factor of 14 was measured compared to exposure conditions at a French Atlantic port (La Rochelle) (Bohé, 2005).

\subsubsection{Aging of ropes in service}

PP/PE ropes of similar diameters to the one shown in Fig. 14.6 have been used in marine operations and for buoy mooring. Break tests were performed on short lengths taken from these applications after service, in order to determine their residual strengths. Fig. 14.8 shows an example of a sample on the test machine.

Table 14.5 provides information on the loss in rope strength measured for different service conditions.

The outer surface that is exposed to sunlight will degrade most quickly, as shown in Fig. 14.7, and the influence of this degradation on the rope strength will depend on exposure time and conditions, and on the rope construction. These ropes are composed of eight circular strands, each of which is made up of twisted rope yarns in layers. Typically there are 12 rope yarns in the outer layer of each strand, which are directly exposed to photochemical ageing, 7 to 12 inner rope yarns (according to the fiber linear weight used, which varies), and in some cases there is also a central twisted 3-rope

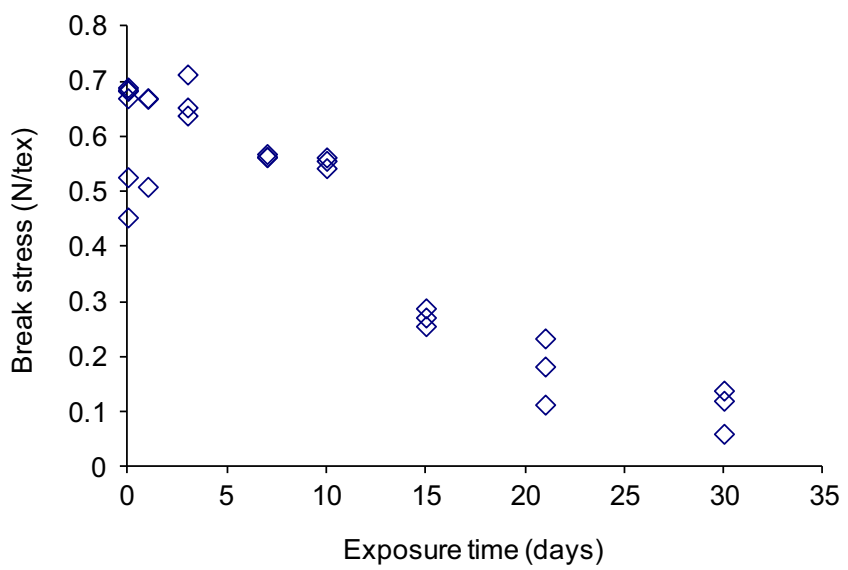

Figure 14.7 Influence of UV exposure on tensile break strength of rope yarns. 


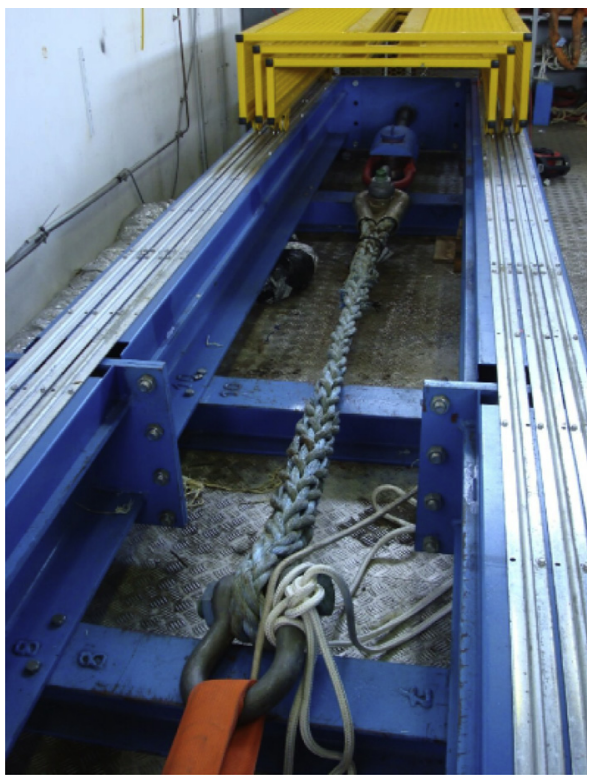

Figure 14.8 Residual tensile strength test on rope sample on a $1000 \mathrm{kN}$ capacity test frame.

Table 14.5 Residual rope strengths, as percentages of nominal break loads, after service and storage

\begin{tabular}{|c|l|l|l|}
\hline $\begin{array}{l}\text { Application } \\
\begin{array}{c}\text { Measured } \\
\text { residual } \\
\text { strength }\end{array}\end{array}$ & $\begin{array}{l}\text { Buoy mooring } \\
\text { 6 months at sea }\end{array}$ & $\begin{array}{l}\text { Buoy } \\
\text { mooring } \\
\text { 6 years at sea }\end{array}$ & $\begin{array}{l}\text { Operations in Africa 1 month, } \\
\text { then storage unprotected 2 years }\end{array}$ \\
\hline
\end{tabular}

yarn layer. In order to establish the degradation profile a complete strand (24 rope yarns) from the 6-year aged mooring line was disassembled, and each rope yarn was tested to failure in tension. Figs. 14.9 and 14.10 show the results. The inner layers appear to be unaffected after service, with strength values in the range of those of the unaged rope yarns shown in Fig. 14.7, while the outer layers have lost a significant amount of their strength.

If we use these data from one strand and assume that they are representative of the behavior of all the strands and that the rope strength efficiency has not changed, we can estimate the aged rope strength to be about $75 \%$ of the initial strength. Given the simplifying assumption that all eight strands are identical to the one tested, this appears to be a reasonable estimation, even though it is a little higher than the measured value of $66 \%$. 
The last column in Table 14.5 shows very low residual strength results for the two samples stored outside for 2 years and indicate that this exposure during storage may have a very strong influence on subsequent behavior. In order to examine this further, a second series of tests was performed. The tests described above were performed in 2006. A sample of the mooring rope aged for 6 years was stored at the Ifremer facilities in Brest; then in 2017, 10 years after the first tests, a second set of 23 rope yarn samples was removed by disassembling a complete strand and testing the rope yarns using the same test fixture.

Fig. 14.10 shows the results. Although initial degradation in service was limited to the outer layers, after 10 further years of light and oxygen exposure the degradation has now developed significantly. This is in line with the comments in Section 14.5.5 above. The outer rope yarn strengths are now very similar to those measured on samples aged in the laboratory for 1 month (Fig. 14.7).

Using these values in the same simple estimation as that applied after 6 years in service the rope strength would now be only $25 \%$ of the nominal initial break load.

It is clear from these results that these PP fiber ropes are sensitive to environmental conditions and that this may have severe consequences in rope applications. As discussed above, this sensitivity can be significantly reduced by including the appropriate additives but this affects cost and is not widespread for these marine applications.

In order to design optimized ropes for long-term applications there are a number of other developments needed. First, it is essential to apply more realistic rope construction models than the simple additive approach applied above. Leech has developed a modeling framework, which takes into account both the helical geometry and the nonlinear force-strain response of the yarns in a hierarchical modeling approach (Leech, 2002).

This is available in a commercial package known as Fiber Rope Modeller, which has proved effective in modeling the tensile response of large rope structures (Leech et al., 1993, 2003; Davies et al., 2006).

For the present case of the braided PP rope it would be possible to use such a model to introduce different rope yarn behavior laws for the outer and inner rope yarns in each strand and hence to obtain a more accurate estimate of rope strength.

Another approach has been developed by Durville (2010), based on finite element modeling with special algorithms to account for the interactions between elements. This has been used to simulate the tension, torsion, and bend over sheave response of braided fiber ropes (Vu et al., 2015; Davies et al., 2013, 2016).

Finally, it should be noted that while oxidation is probably the main degradation mechanism to consider, these marine ropes are also subjected to a range of mechanical loads in service. Unfortunately, while data do exist for fatigue loading of polyester fiber ropes, as a result of their extensive use for the offshore oil and gas industry in floating platform mooring lines (Banfield et al., 2000), this is not the case for PP fiber ropes. The polyolefin fibers are also known to be sensitive to creep, so their use in long-term marine applications is not recommended without extensive testing on the actual rope product to be employed in service. 


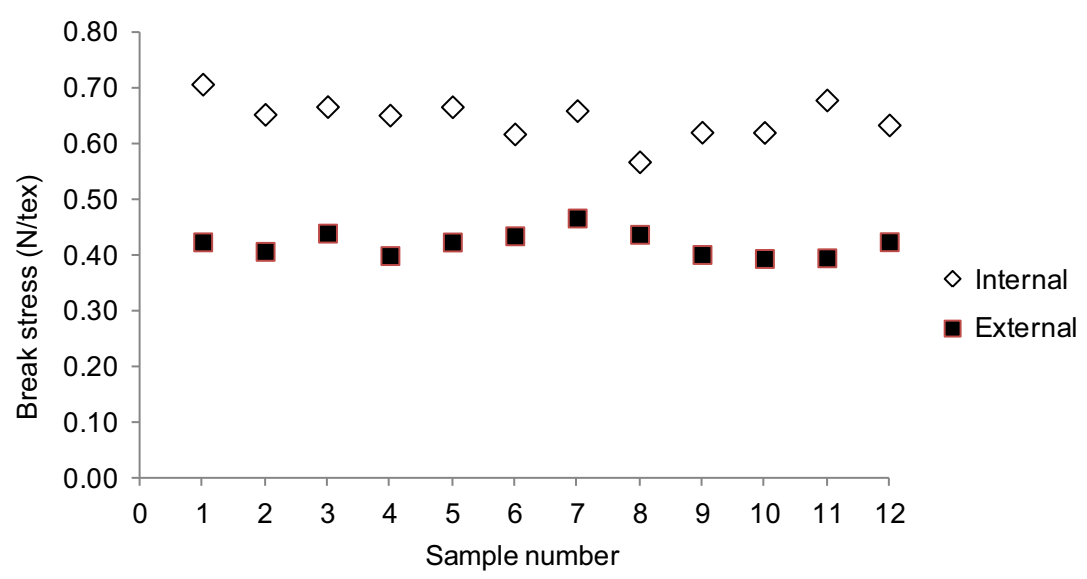

Figure 14.9 Residual strength of rope yarns from one strand of 6-year aged mooring line.

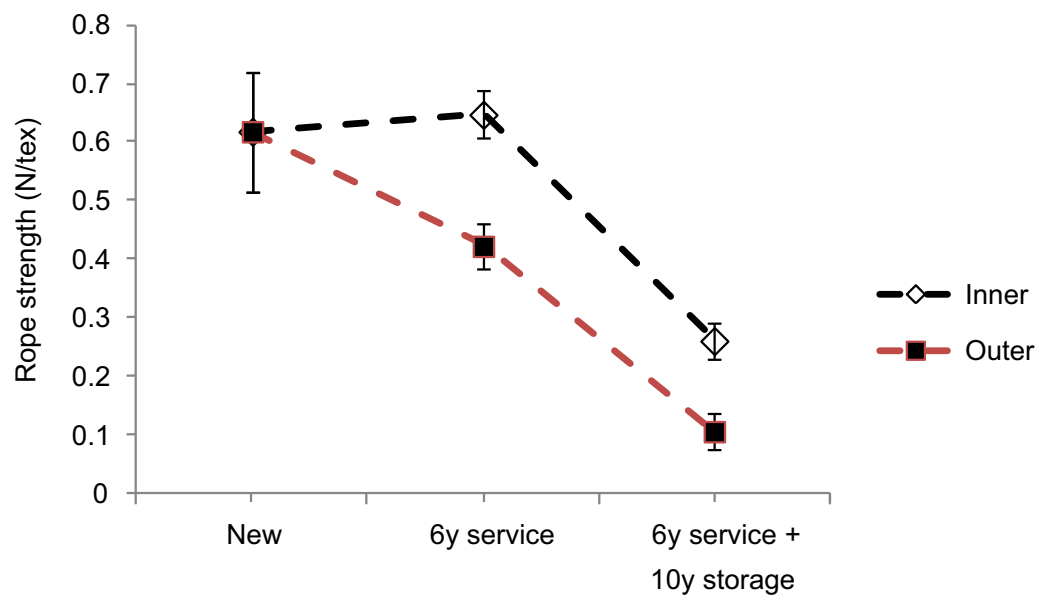

Figure 14.10 Rope yarn strengths after 6 years in service and 10 years storage.

\subsection{Conclusions}

As soon as the method for its stereospecific synthesis was discovered, one half century ago, polypropylene appeared as a very interesting fiber forming polymer owing to its low cost, easy processability, hydrophobicity, and relatively high tenacity. Considerable worldwide efforts, in the elapsed period, allowed the degree of stereoregularity and the molar mass distribution to be controlled more and more accurately, and the oxidizability, which is the weakest PP characteristic, to be reduced. At the same time, new processing methods profiting from the peculiarities of the PP rheological behavior, especially its high viscoelastic character in molten state, were created. As a result, a wide variety of PP fibers, offering a broad range of diameters, stiffnesses, 
tenacities, photo and thermal stabilities, etc. is now available on the market. It is thus not surprising to find PP fibers in an unequalled variety of applications, from carpets to geotextiles and ropes.

\section{Abbreviations}

$\begin{array}{ll}\text { GPC } & \text { Gel permeation chromatography } \\ \text { HALS } & \text { Hindered amine light stabilizers } \\ \text { i-PP } & \text { Isotactic polypropylene } \\ \text { MWD } & \text { Molecular weight distribution } \\ \text { ODCB } & \text { Ortho dichloro benzene } \\ \text { PE } & \text { Polyethylene } \\ \text { PET } & \text { Poly(ethylene terephthalate) } \\ \text { PP } & \text { Polypropylene } \\ \text { PS } & \text { Polystyrene } \\ \text { S-PP } & \text { Syndiotactic polypropylene } \\ \text { TCB } & \text { Trichlorobenzene } \\ \text { UV } & \text { Ultra violet } \\ \text { ZN } & \text { Ziegler Natta }\end{array}$

\section{References}

Aboulfaraj M, G'Sell C, Ulrich B, Dahoun A: In situ observation of the plastic deformation of polypropylene spherulites under uniaxial tension and simple shear in the scanning electron microscope, Polymer 36(4):731-742, 1995.

Aguilar M, Vega JF, Peña B, Martínez-Salazar J: Novel features of the rheological behaviour of metallocene catalysed atactic polypropylene, Polymer 44(5):1401-1407, 2003.

Aizenshtein EM: World chemical fibre and thread production in 2003, Fibre Chem 36(6): 467-482, 2004.

Aizenshtein EM: Prices for petrochemical raw materials and synthetic fibres and thread in the second half of 2005, Fibre Chem 38(2):164-178, 2006.

Aizenshtein EM, Efremov VN: Production and use of polypropylene fibres and yarn, Fibre Chem 38(5):345-350, 2006.

Andreassen E, Myrhe OJ, Hinrichsen EL, Grøstad K: Effects of processing parameters and molecular weight distribution on the tensile properties of polypropylene fibers, $J$ Appl Polym Sci 52(10):1505-1517, 1994.

Aouinti M, Bertrand P, Poncin-Epaillard F: Characterization of polypropylene surface treated in a CO2 plasma, Plasmas Polym 8(4):225-236, 2003.

Aratani N, Katada I, Nakayama K, Terano M, Taniike T: Development of high-throughput chemiluminescence imaging instrument for parallel evaluation of polymer lifetime, Polym Degrad Stab 121:340-347, 2015.

Arranz-Andrés J, Guevara JL, Velilla T, Quijada R, Benavente R, Pérez E, Cerrada ML: Syndiotactic polypropylene and its copolymers with alpha-olefins. Effect of composition and length of comonomer, Polymer 46(26):12287-12297, 2005. 
Astruc A, Bartolomeo P, Fayolle B, Audouin L, Verdu J: Accelerated oxidative ageing of polypropylene fibers in aqueous medium under high oxygen pressure as studied by thermal analysis, Polym Test 23(8):919-923, 2004.

Bajer K: U.Braun. Different aspects of the accelerated oxidation of polypropylene at increased pressure in an autoclave with regard to temperature, pretreatment and exposure media, Polym Test 37:102-111, 2014.

Balzano L, Ma Z, Cavallo D, Van Erp TB, Fernandez-Ballester L, Peters GWM: Molecular aspects of the formation of shish-kebab in isotactic polypropylene, Macromolecules 49(10):3799-3809, 2016.

Banfield SJ, Versavel T, Snell RO, Ahilan RV: Fatigue curves for polyester moorings - a stateof-the-art review, paper OTC 12175, May 2000.

Berber E, Horzum N, Hazer B, Demir MM: Solution electrospinning of polypropylene-based fibers and their application in catalysis, Fibers Polym 17(5):760-768, May 2016.

Black RM, Lyons BJ: Effect of high-energy radiation on polypropylene, Nature 180: 1346-1347, 1957.

Bohé V (Ph.D. thesis): Mechanical behaviour of sailcloth (in French), University Paris 6.

Bolland JL, Gee G: Kinetic studies in the chemistry II - the kinetics of oxidation of unconjugated olefins, Trans Faraday Soc 42:236-243, 1946.

Bolland JL, Gee G: Kinetic studies in the chemistry of rubbers and related materials III thermochemistry and mechanisms of olefins oxidation, Trans Faraday Soc 42:244-252, 1946.

Bond EB, Spruiell JE: The effects of atacticity, comonomer content, and configurational defects on the equilibrium melting temperature of monoclinic isotactic polypropylene, $J$ Appl Polym Sci 81(1):229-236, 2001.

Bond EB, Spruiell JE: Melt spinning of metallocene catalyzed polypropylenes. II. As-spun filament structure and properties, J Appl Polym Sci 82(13):3237-3247, 2001.

Bond EB, Spruiell JE: Melt spinning of metallocene catalyzed polypropylenes. I. On-line measurements and their interpretation, J Appl Polym Sci 82(13):3223-3236, 2001.

Cannon CG: Orientation processes in the drawing of dry gel films of polyethylene and polypropylene, Polymer 23(8):1123-1128, 1982.

Cao J, Sbarski I: Determination of the enthalpy of solid phase transition for isotactic polypropylene using a modified DSC technique, Polymer 47(1):27-31, 2006.

Chen HB, Karger-Kocsis J, Wu JS, Varga J: Fracture toughness of $\alpha$ - and $\beta$-phase polypropylene homopolymers and random- and block-copolymers, Polymer 43(24): 6505-6514, 2002.

Chen JH, Tsai FC, Nien YH, Yeh PH: Isothermal crystallization of isotactic polypropylene blended with low molecular weight atactic polypropylene. Part I. Thermal properties and morphology development, Polymer 46(15):5680-5688, 2005.

Choi D, White JL: Crystallization and orientation development in fiber and film processing of polypropylenes of varying stereoregular form and tacticity, Polym Eng Sci 44(2):210-222, 2004.

Corradini P, Natta G, Ganis P, Temussi PA: Crystal structure of syndiotactic polypropylene, J Polym Sci Polym Symp 16(5):2477-2484, 1967.

Coulon G, Castelein G, G'Sell C: Scanning force microscopic investigation of plasticity and damage mechanisms in polypropylene spherulites under simple shear, Polymer 40(1): 95-110, 1999.

Davies P, Bouquet P, Conte M, Deuff A: Tension-torsion behavior of deepwater synthetic mooring lines. In Proc offshore technology conference OTC17872, 2006. 
Davies P, Lacotte NP, Kibsgaard G, Craig R, Cannell D, François S, Lodeho O, Konate K, Mills S, François M, Defoy A-L, Durville D, Vu D, Gilmore J, Sherman D. In Bend over sheave durability of fibre ropes for deep sea handling OMAE2013-11332, OMAE, June 2013. Nantes.

Davies P, Durville D, Vu TD: The influence of torsion on braided rope performance, modelling and tests, Appl Ocean Res 59:417-423, 2016.

De Rosa C, Auriemma F: Structure and physical properties of syndiotactic polypropylene: a highly crystalline thermoplastic elastomer, Prog Polym Sci 31(2):145-237, 2006.

De Rosa C, Auriemma F, Vinti V, Galimberti M: Equilibrium melting temperature of syndiotactic polypropylene, Macromolecules 31:6206-6210, 1998.

De Rovère A, Shambaugh RL, O'Rear EA: Investigation of gravity-spun, melt-spun, and meltblown polypropylene fibers using atomic force microscopy, J Appl Polym Sci 77(9): 1921-1937, 2000.

De Santis F, Adamovsky S, Titomanlio G, Schick C: Isothermal nanocalorimetry of isotactic polypropylene, Macromolecules 40(25):9026-9031, 2007.

Decker C, Mayo FR: Aging and degradation of polyolefins. II. $\gamma$-initiated oxidations of atactic polypropylene, J Polym Sci Polym Chem Ed 11(11):2847-2877, November 1973.

Denisov ET: Mechanism of regeneration of hindered nitroxyl and aromatic amines, Polym Degrad Stab 25(2-4):209-215, 1989.

Durville D: Simulation of the mechanical behaviour of woven fabrics at the scale of fibers, Int $J$ Mater Form 3:1241-1251, 2010.

El Maaty MIA, Bassett DC, Olley RH, Dobb MG, Tomka JG, Wang I-C: On the formation of defects in drawn polypropylene fibres, Polymer 37(2):213-218, 1996.

Emanuel NM, Buchachenko AL: Chemical physics of polymer degradation and stabilization, VNU Sci Press (Utrecht), 1987.

Evans JM: Gel permeation chromatography: a guide to data interpretation, Polym Eng Sci 13(6): 401-408, 1973.

Fatou JG: Melting temperature and enthalpy of isotactic polypropylene, Eur Polym J 7(8): 1057-1064, 1971.

Fayolle B, Richaud E, Verdu J, Farcas F: Embrittlement of polypropylene fibre during thermal oxidation, J Mater Sci 43(3):1026-1032, 2008.

Fayolle B, Richaud E, Colin X, Verdu J: Review: degradation-induced embrittlement in semicrystalline polymers having their amorphous in rubbery state, J Mater Sci 43:6999-7012, 2008.

Fetters LJ, Lohse DJ, Colby RH: Chain dimensions and entanglement spacings. In Mark JE, editor: Physical properties of polymers handbook, Springer Science, pp 447-454 (chapter 25).

Fichera A, Zannetti R: Thermal Properties of Isotactic polypropylene quenched from the melt and annealed, Die Makromol Chem 176:1885-1892, 1975.

Franceschini FC, Tavares TT da R, Greco PP, Bianchini D, Chiarello Stedile F, Galland GB, dos Santos JHZ, Soares JBP: Polypropylene obtained with in situ supported metallocene catalysts, J Mol Catal A Chem 202(1-2):127-134, 2003.

François-Heude A, Richaud E, Desnoux E, Colin X: Influence of temperature, UV-light wavelength and intensity on polypropylene photothermal oxidation, Polym Degrad Stab 100:10-20, 2014.

François-Heude A, Richaud E, Desnoux E, Colin X: A general kinetic model for the photothermal oxidation of polypropylene, J Photochem Photobiol A Chem 296:48-65, 2015. 
Gensler R, Plummer CJG, Kausch H-H, Kramer E, Pauquet J-R, Zweifel H: Thermo-oxidative degradation of isotactic polypropylene at high temperatures: phenolic antioxidants versus HAS, Polym Degrad Stab 67(2):195-208, 2000.

Goldstein HS: Selecting the right mesh, Hernia 3(1):23-26, 1999.

Gregor-Svetec D, Sluga F: High modulus polypropylene fibers. I. Mechanical properties, J Appl Polym Sci 98(1):1-8, 2005.

Gugumus F: Physico-chemical aspects of polyethylene processing in an open mixer6. Discussion of hydroperoxide formation and decomposition, Polym Degrad Stab 68(3):337-352, 2000.

Gupta VB, Mondal SA, Bhuvanesh YC: Spinning speed-throughput rate relationships for polyester, nylon, and polypropylene fibers, J Appl Polym Sci 65(9):1773-1788, 1997.

Hadley DW, Ward IM: Mechanical anisotropy at small strains. In Ward IM, editor: Structure and properties of oriented polymers, Springer, pp 269-333 (chapter 6).

Haillant O, Lemaire J: Natural and artificial photo-aging of non-stabilized and pigmented, hindered-amine stabilized propylene-ethylene copolymers, Polym Degrad Stab 91(11): 2748-2760, 2006.

Harding GW, van Reenen AJ: Polymerisation and structure-property relationships of Ziegler-Natta catalysed isotactic polypropylenes, Eur Polym J 47(1):70-77, 2011.

Horrocks AR, Valinejad K, Crighton JS: The influence of fibre production history and stress on the durability of polypropylene, Polym Degrad Stab 43(1):81-91, 1994.

Howe DV: Polypropylene, isotactic. In Mark JE, editor: Polymer data handbook, Oxford University Press, Inc., pp 780-786.

Hsuan YG, Li M: Temperature and pressure effects on the oxidation of high-density polyethylene geogrids, Geotext Geomembr 23(1):55-75, 2005.

http://www.ampolymer.com/http://www.ampolymer.com/Mark-HouwinkParameters.html.

Huang J, Rempel GL: Ziegler-Natta catalysts for olefin polymerization: mechanistic insights from metallocene systems, Prog Polym Sci 20(3):459-526, 1995.

Ikeda Y, Ohta T: The influence of chain entanglement density on ultra-drawing behavior of ultra-high-molecular-weight polypropylene in the gel-casting method, Polymer 49(2): 621-627, 2008.

Isaeva VI, Aizenshtein EM, Soboleva ON: World production and use of polypropylene fibres and thread. A review, Fibre Chem 29(5):269-281, 1997.

Jipa S, Setnescu R, Setnescu T, Zaharescu T: Efficiency assessment of additives in thermal degradation of i-PP by chemiluminescence I. Triazines, Polym Degrad Stab 68(2): 159-164, 2000.

Kalantari B, Semnani Rahbar R, Mojtahedi MRM, Shoushtari M, Khosroshahi A: Production and characterization of polypropylene fiber upon addition of selective peroxide during melt spinning and comparison with conventional polypropylene fibers, J Appl Polym Sci 105(4): 2287-2293, 2007.

Kaminsky W: Polymerization catalysis, Catal Today 62(1):23-34, 2000.

Kang Y-A, Kim K-H, Ikehata S, Ohkoshi Y, Gotoh Y, Nagura M, Urakawa H: In-situ analysis of fiber structure development for isotactic polypropylene, Polymer 52(9):2044-2050, 2011.

Klemchuk PP: Influence of pigments on the light stability of polymers: a critical review, Polym Photochem 3(1):1-27, 1983.

Koerner RM, Lord Jr AE, Hsuan YH: Arrhenius modeling to predict geosynthetic degradation, Geotext Geomembr 11(2):151-183, 1992.

Kohler WH, McHugh AJ: Sensitivity analysis of low-speed melt spinning of isotactic polypropylene, Chem Eng Sci 62(10):2690-2697, 2007. 
Kongkitkul W, Tatsuoka F: A theoretical framework to analyse the behaviour of polymer geosynthetic reinforcement in temperature-accelerated creep tests, Geosynth Int 14(1): 23-38, 2007.

Kucher NK, Zemtsov MP, Danil'chuk EL: Short-term creep and strength of fibrous polypropylene structures, Strength Mater 39(6):620-629, 2007.

Larrondo L, St John Manley R: Electrostatic fiber spinning from polymer melts. I. Experimental observations on fiber formation and properties. Journal of Polymer Science, Polym Phys Ed 19(6):909-920, 1981.

Leech C: The modelling of friction in polymer fibre ropes, Int J Mech Sci Int J Mech Sci 44(3): 621-643, 2002.

Leech CM, Hearle JWS, Overington MS, Banfield SJ: Modelling tension and torque properties of fibre ropes and splices. In Proceeding of the third international offshore and polar engineering conference Singapore, 1993.

Leech CM, Banfield SJ, Overington MS, Lemoel M: The prediction of cyclic load behaviour and modulus modulation for polyester and other large synthetic fibre ropes. In Proc. Oceans, 2003.

Lezak E, Bartczak Z, Galeski A: Plastic deformation behavior of $\beta$-phase isotactic polypropylene in plane-strain compression at room temperature, Polymer 47(26): 8562-8574, 2006.

Li M, Hsuan YG: Temperature and pressure effects on the degradation of polypropylene tape yarns-depletion of antioxidants, Geotext Geomembr 22(6):511-530, 2004.

Li JX, Cheung WL, Jia D: A study on the heat of fusion of $\beta$-polypropylene, Polymer 40(5): 1219-1222, 1999.

Libster D, Aserin A, Garti N: Review: advanced nucleating agents for polypropylene, Polym Adv Tech 18(9):685-695, 2007.

Loos J, Schimanski T: Morphology-mechanical property relations in syndiotactic polypropylene (sPP) fibers, Polym Eng Sci 40(3):567-572, 2000.

Lu FM, Spruiell JE: The influence of resin characteristics on the high speed melt spinning of isotactic polypropylene. II. On-line studies of diameter, birefringence, and temperature profiles, J Appl Polym Sci 34(4):1541-1556, 1987.

Lu FM, Spruiell JE: The influence of resin characteristics on the high speed melt spinning of isotactic polypropylene. I. Effect of molecular weight and its distribution on structure and mechanical properties of as-spun filaments, J Appl Polym Sci 34(4):1521-1539, 1987.

Marigo A, Marega C, Zannetti R, Paganetto G, Canossa E, Coletta F, Gottardi F: Crystallization of the $\gamma$-form of isotactic poly(propylene), Macromol Chem Phys 190(11):2805-2813, 1989.

Matsuo M, Sawatari C, Nakano T: Ultradrawing of isotactic polypropylene films produced by gelation/crystallization from solutions, Polym J 18(10):759-774, 1986.

McKenna H, Hearle J, O'Hear N: Handbook of fibre rope technology, Cambridge, 2004, Woodhead Publishing limited.

Meille SV, Bruckner S, Porzio W: $\gamma$-Isotactic polypropylene. A structure with nonparallel chain axes, Macromolecules 23(18):4114-4121, 1990.

Miller RL: On the existence of near-range order in isotactic polypropylenes, Polymer 1: 135-143, 1960.

Moisidis E, Curiskis JI, Brooke-Cowden GL: Improving the reinforcement of parastomal tissues with marlex ${ }^{\circledR}$ mesh, Dis Colon Rectum 43(1):55-60, 2000.

Mueller W, Buettgenbach B, Jakob I, Mann H: Comparison of the oxidative resistance of various polyolefin geotextiles, Geotext Geomembr 21(5):289-315, 2003. 
Myers CL: Polypropylene, atactic. In Mark JE, editor: Polymer data handbook, Oxford University Press, Inc., pp 772-775.

Nadella HP, Henson HM, Spruiell JE, White JL: Melt spinning of isotactic polypropylene : structure development and relationship to mechanical properties, J Appl Polym Sci 21(11): 3003-3022, 1977.

Osawa S, Porter RS: Uniplanar deformation of isotactic polypropylene: 2, Phase Structure 35(3):545-550, 1994.

Paulsen SB, Kramer SL: A predictive model for seismic displacement of reinforced slopes', Geosynth Int 11(6):407-428, 2004.

Pospísil J: Chemical and photochemical behaviour of phenolic antioxidants in polymer stabilization-a state of the art report, Polym Degrad Stab 40(2):217-232, 1993.

Pospísil J: Chemical and photochemical behaviour of phenolic antioxidants in polymer stabilization: a state of the art report, part II, Polym Degrad Stab 39(1):103-115, 1993.

Qin Y: Global fibres overview. In Synthetic fibres raw materials committee meeting at APIC 2014, Pattaya, May 16, 2014, 2014.

Reano AF, Domenek S, Pernes M, Beaugrand J, Allais F: Ferulic acid-based Bis/Trisphenols as renewable antioxidants for polypropylene and poly(butylene succinate), ACS Sustain Chem Eng 4(12):6562-6571, 2016.

Richaud E: Kinetic modelling of phenols consumption during polyethylene thermal oxidation, Eur Polym J 49(8):2223-2232, 2013.

Richaud E, Farcas F, Bartoloméo P, Fayolle B, Audouin L, Verdu J: Effect of oxygen pressure on the oxidation kinetics of unstabilised polypropylene, Polym Degrad Stab 91(2): 398-405, 2006.

Richaud E, Farcas F, Divet L, Benneton JP: Accelerated ageing of polypropylene geotextiles, the effect of temperature, oxygen pressure and aqueous media on fibers-methodological aspects, Geotext Geomembr 26(1):71-81, 2008.

Richaud E, Farcas F, Fayolle B, Audouin L, Verdu J: Accelerated ageing of polypropylene stabilized by phenolic antioxidants under high oxygen pressure, J Appl Polym Sci 110(6): 3313-3321, 2008.

Richaud E, Fayolle B, Verdu J: Polypropylene stabilization by hindered phenols - kinetic aspects, Polym Degrad Stab 96(1):1-11, 2011.

Rincon-Rubio LM, Fayolle B, Audouin L, Verdu J: A general solution of the closed-loop kinetic scheme for the thermal oxidation of polypropylene, Polym Degrad Stab 74(1):177-188, 2001.

Rodriguez-Arnold J, Zhang A, Z.D Cheng S, J Lovinger A, T Hsieh E, Chu P, Johnson TW, Honnell KG, Geerts RG, Palackal SJ, Hawley GR, Bruce Welch M: Crystallization, melting and morphology of syndiotactic polypropylene fractions: 1 . Thermodynamic properties, overall crystallization and melting, Polymer 35(9):1884-1895, 1994.

Sadiqul Islam GM, Das Gupta S: Evaluating plastic shrinkage and permeability of polypropylene fiber reinforced concrete, Int J Sustain Built Environ 5(2):345-354, 2016.

Safa L, Zaki O, Leprince Y, Feigenbaum A: Evaluation of model compounds-polypropylene film interactions by Fourier transformed infrared spectroscopy (FTIR) method, Packag Technol Sci 21(3):149-157, 2008.

Sakurai T, Nozue Y, Kasahara T, Mizunuma K, Yamaguchi N, Tashiro K, Amemiya Y: Structural deformation behavior of isotactic polypropylene with different molecular characteristics during hot drawing process, Polymer 46(20):8846-8858, 2005.

Schwarz I, Stranz M, Bonnet M, Petermann J: Changes of mechanical properties in coldcrystallized syndiotactic polypropylene during aging, Colloid Polym Sci 279(5): 506-512, 2001. 
Schwarzenbach K, Gilg B, Müller D, Knobloch G, Pauquet JR, Rota-Graziosi P, Schmitter A, Zingg J, Kramer E: Antioxidants. In Zweifel H, editor: Plastic additives handbook, ed 5, Munich, 2000, Hanser Publishers, pp 1-139 (chapter 1).

Seguela R: Critical review of the molecular topology of semicrystalline polymers: the origin and assessment of intercrystalline tie molecules and chain entanglements, J Polym Sci Part B Polym Phys 43(14):1729-1748, 2005.

Shavit-Hadar L, Rein DM, Khalfin DL, Ann E, Terry AE, Cohen Y: The effect of moderate pressure on the crystalline structure of oriented polypropylene tapes using in situ X-ray diffraction, Polym Adv Technol 18(9):766-770, 2007.

Shi G, Huang B, Zhang J: Enthalpy of fusion and equilibrium melting point of the $\beta$-form of polypropylene, Macromol Rapid Commun 5(9):573-578, 1984.

Sowinski P, Piorkowska E, Boyer SAE, Haudin J-M: Nucleation of crystallization of isotactic polypropylene in the gamma form under high pressure in nonisothermal conditions, Eur Polym J 85:564-574, 2016.

Stakne K, Smole MS, Kleinschek KS, Jaroschuk A, Ribitsch V: Characterisation of modified polypropylene fibres, J Mater Sci 38(10):2167-2169, 2003.

Suits LD, Hsuan YG: Assessing the photo-degradation of geosynthetics by outdoor exposure and laboratory weatherometer, Geotext Geomembr 21(2):111-122, 2003.

Tidjani A, Watanabe Y: Study of the effect of $\gamma$-dose rate on the oxidation of polypropylene, J Appl Polym Sci 60:1839-1845, 1996.

Turner-Jones A: Development of the $\gamma$-crystal form in random copolymers of propylene and their analysis by dsc and x-ray methods, Polymer 12(8):487-508, 1971.

Uehara H, Yamazaki Y, Kanamoto T: Tensile properties of highly syndiotactic polypropylene, Polymer 37(1):57-64, 1996.

Van Krevelen DW: Properties of Polymer - their correlation with chemical structure; their numerical estimation and prediction for additive group contribution, ed 3, Amsterdam, Lausanne, New York, Oxford, Shannon, Tokyo, 1990, Elsevier.

Varga J: Review: supermolecular structure of isotactic polypropylene, J Mater Sci 27: 2557-2579, 1992.

Varga J, Mudra I, Ehrenstein GW: Crystallization and melting of $\beta$-nucleated isotactic polypropylene, J Therm Anal Calorim 56(3):1047-1057, 1999.

Varma-Nair M, Agarwal PK: Quiesent crystallization kinetics of nucleated metallocene and ZN isotactic polypropylenes, J Therm Anal Calorim 59(1-2):483-495, 2000.

Verdu J, Rychly J, Audouin L: Synergism between polymer antioxidants-kinetic modelling, Polym Degrad Stab 79(3):503-509, 2003.

Vu TD, Davies P, Durville D: Finite element simulation of the mechanical behaviour of synthetic braided ropes and validation on a tensile test, Int J Sol Struct 58:106-116, 2015.

Ward AL, Lu X, Huang Y, Brown N: The mechanism of slow crack growth in polyethylene by an environmental stress cracking agent, Polymer 32(12):2172-2178, 2001.

Wei QF, Mather RR, Wang XQ, Fotheringham AF: Functional nanostructures generated by plasma-enhanced modification of polypropylene fibre surfaces, J Mater Sci 40(20): 5387-5392, 2005.

Xu JT, Guan FX, Yasin T, Fan ZQ: Isothermal crystallization of metallocene-based polypropylenes with different isotacticity and regioregularity, J Appl Polym Sci 90(12): 3215-3221, 2003.

Yu B, Lu Qi L, Ye JZ, Sun H: The research of radar absorbing property of bicomponent fiber with infrared camouflage, J Polym Res 14(2):107-113, 2007.

Zambelli A, Natta G, I Pasquon: Polymérisation du Propylène à Polymère Syndiotactique, J Polym Sci C 4(1):411-426, 1963. 
Zhang XC, Cameron RE: The morphology of irradiated isotactic polypropylene, J Appl Polym Sci 74(9):2234-2242, 1999.

Zhang X, Zhao Y, Wang Z, Zheng C, Dong X, Su Z, Sun P, Wang D, Han CC, Xu D: Morphology and mechanical behavior of isotactic polypropylene (iPP)/syndiotactic polypropylene (sPP) blends and fibers, Polymer 46(16):5956-5965, 2005.

Zhang H, Lee Y, Park J, Lee D, K.B Yoon: Control of molecular weight distribution for polypropylene obtained by commercial Ziegler-Natta catalyst: effect of temperature, Polym Bull 67(8):1519-1527, 2011.

Zhongde X, Mays J, Xuexin C, Hadjichristidis N, Schilling FC, Bair HE, Pearson DS, Fetters LJ: Molecular characterization of poly(2-methyl-1,3-pentadiene) and its hydrogenated derivative, atactic polypropylene, Macromolecules 18(12):2560-2566, 1985.

Zou XX, Wei Yang W, Zheng GQ, Xie BH, Yang MB: Crystallization and phase morphology of injection-molded isotactic polypropylene (iPP)/syndiotactic polypropylene (sPP) blends, J Polym Sci B Polym Phys 45(21):2948-2955, 2007. 